\title{
DNA Methylation and SNPs of ABCA1 Gene Promoter Affect Gene Expression and Involve in the Pathological Mechanism of Ischemic Stroke
}

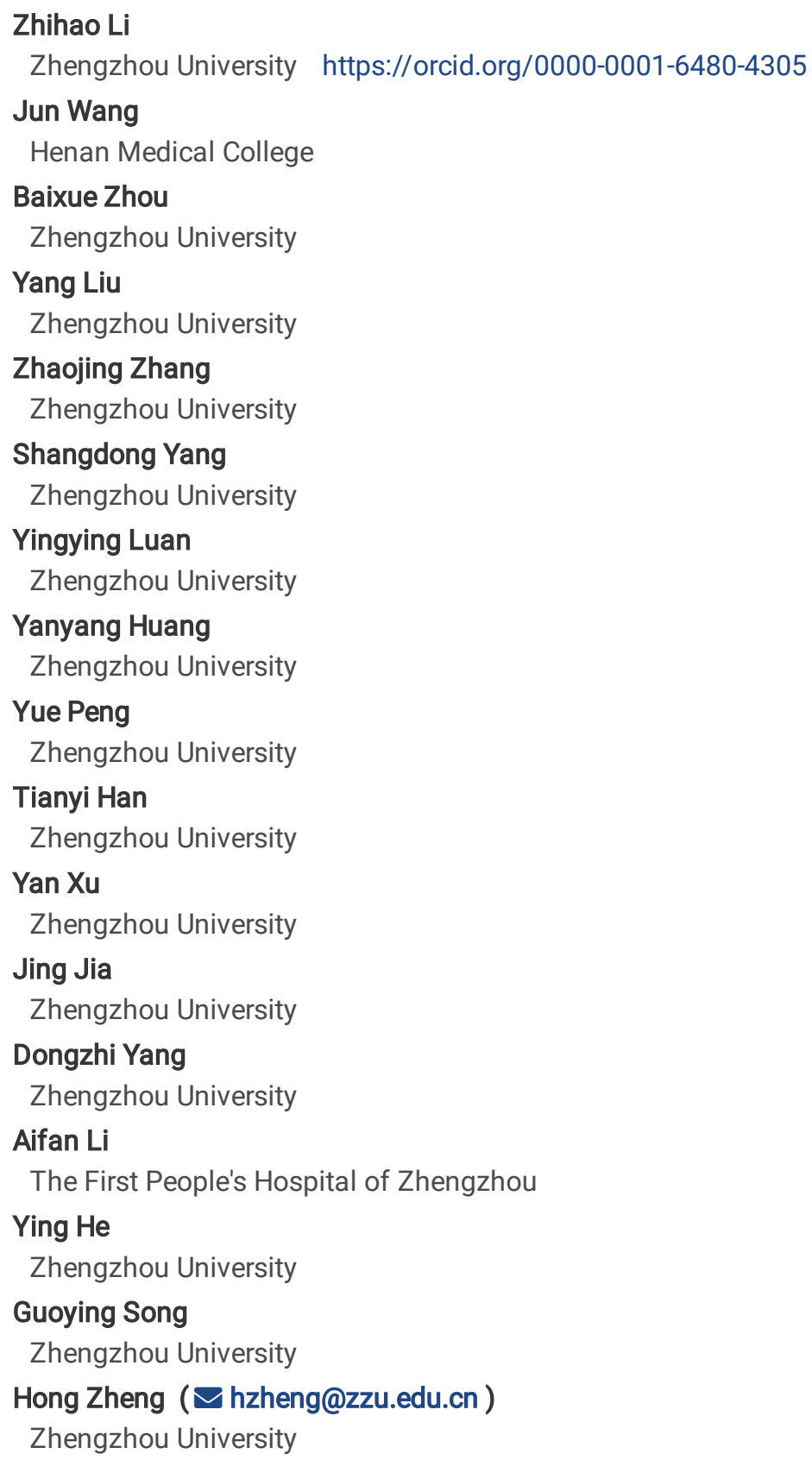


License: @ (1) This work is licensed under a Creative Commons Attribution 4.0 International License. Read Full License 


\section{Abstract}

ATP binding cassette subfamily A1 (ABCA1) is a key protein in the formation of mature high density lipoprotein (HDL), which plays a crucial role in atherosclerosis. Accumulating evidence has shown that the expression levels of the $A B C A 1$ gene are upregulated in ischemic stroke (IS) patients. However, the mechanism remains elusive. We hypothesized that DNA methylation and SNPS of $A B C A 1$ gene promoter affect the expression levels of $A B C A 1$ gene and involve in the pathological mechanism of IS. 100 patients with IS and 100 healthy controls were enrolled in the present study. Initially, the mRNA expression levels of $A B C A 1$ gene were examined by qPCR and the methylation levels was detected by MethyTarget sequencing. Then, rs1800976, rs1800977, rs2246298, rs2437817, rs2740483, rs539621172 in promoter region of $A B C A 1$ gene were selected for genotyping. Finally, the relationship between the methylation of $A B C A 1$ gene and gene expression was verified by constructing THP-1 foam cell model. The mRNA expression levels of $A B C A 1$ gene in the IS group were significantly higher than those in controls $(P<0.05) .17 \mathrm{CpG}$ sites in the promoter of $A B C A 1$ gene were analyzed and the DNA methylation levels of CpG1, CpG7 and CpG15 sites in IS group was significantly lower than control group $(P<0.05)$. Rs2740483, rs1800977 and rs2437817 were significantly correlated with CpG1. Rs1800977 was significantly correlated with CpG3. In summary, DNA methylation and rs 2740483, rs 1800977, rs2437817 of $A B C A 1$ gene promoter affect the expression levels of $A B C A 1$ gene, change the clearance rate of intracellular lipids, and participate in the pathogenesis of IS.

\section{Introduction}

Ischemic Stroke (IS) is a nervous system disease characterized by cerebral artery stenosis or occlusion, resulting in hypoxia, ischemia or necrosis of cerebral perfusion area. It is the leading cause of morbidity and mortality in the world. Atherosclerosis (AS) is an important pathophysiological basis for the occurrence of IS (Virani SS et al., 2020). Studies have shown that more than 70\% of IS patients have atherosclerosis in different degrees (Banerjee $C$ and Chimowitz MI, 2017). The main pathological feature of the early AS is the excessive cholesterol deposition of cholesterol arterial endothelium, which promotes the accumulation of many foam cells, and gradually develops the fatty streaks into atherosclerotic plaques (Galkina E and Ley K, 2009;Huo Y and Ley K, 2001;Kaplan M and Aviram M, 2001;McGill HC, Jr. et al., 2000;Skalen K et al., 2002). The accumulation of monocytes in circulating blood at the injured intima and adhesion to vascular endothelium is the key step of fatty streak formation. Reverse cholesterol transport (RCT) plays an important role in maintaining intracellular lipid balance and preventing the formation of AS (Favari E et al., 2015). ATP binding cassette subfamily $A 1$ ( $A B C A 1)$ is a key protein in the formation of mature high density lipoprotein (HDL), and can inhibit the inflammatory response in the process of atherosclerosis.

DNA methylation refers to the formation of 5-methylcytosine (5-mc) from S-adenosylmethionine (SAM) under the action of DNA methyltransferase (DNMT) (Das PM and Singal R, 2004). Methylation usually occurs on cytosine in CpG islands. The CpG island in the promoter region is usually in the state of no methylation, but in some disease states, the methylation state of the promoter region will change, so as to regulate gene expression. Gomez uriz et al. found that the methylation levels of $80 \mathrm{CpG}$ loci in stroke patients were different by using methylation microarray, and the difference of DNA methylation can be used as a potential marker of stroke (GomezUriz AM et al., 2015).

Single nucleotide polymorphisms (SNPs) may affect the level of DNA methylation in genome CpG island region and regulate gene expression, participating in the pathogenesis of diseases. Gibbs et al. analyzed the correlation between genetic variation and DNA methylation and mRNA expression in 600 human brain samples, and found a large number of cis regulatory sites that regulate mRNA expression, as well as quantitative trait sites that can influence the methylation degree of gene CpG sites (Gibbs JR et al., 2010). Cheung et al. analyzed the allelic and non allelic effects of DNA methylation of $\mathrm{CpG}$ sites in the whole genome by combining the whole genome information and ferrous sulfite sequencing results of 910 samples. The results showed that about $69.7 \%$ of the $1043828 \mathrm{CpG}$ sites involved were significantly related to allelic methylation or non allelic methylation (Cheung WA et al., 2017). However, the effects of SNPs of $A B C A 1$ on $\mathrm{CpG}$ methylation level and the gene expression in IS patients need further explored. Thus, we proposed a hypothesis that DNA Methylation and SNPs of $A B C A 1$ gene promoter affect gene expression and participate in the pathological mechanism of IS.

Therefore, in the present study, the mRNA expression levels of $A B C A 1$ gene in IS patients and normal controls were detected by quantitative real-time PCR firstly. Then, the methylation levels of $A B C A 1$ gene promoter were tested by MethyTarget sequencing. Next, six SNPs (rs1800976, rs1800977, rs2246298, rs2437817, rs2740483, rs539621172) in promoter region of $A B C A 1$ gene were selected for genotyping. Finally, THP-1 foam cell model was constructed to explore the relationship between gene expression and methylation of $A B C A 1$ gene. 


\section{Material And Methods \\ Study Populations}

100 IS patients recruited from departments of neurology in the First Affiliated Hospital of Henan University of Chinese Medicine from March 2017 to March 2018 (54 males and 46 females, mean age of $59.18 \pm 11.79$ years) were included in our study. The IS was defined by a loss of global or focal cerebral function persisting for $>24 \mathrm{~h}$ with corresponding infarction on brain imaging with a probable vascular cause. Brain imaging was carried out by computed tomography and/or magnetic resonance imaging (MRI), and ancillary diagnostic investigations and standardized blood tests were also performed. Patients with cerebral hemorrhage, atrial fibrillation, hyperthyroidism, cardioembolic stroke, venous thrombosis, peripheral vascular diseases, liver disorders or kidney diseases were excluded from the study.

The control group consisted of 100 (48 males and 52 females, mean age of $57.37 \pm 12.32$ years) selected from the same demographic area. And they were well matched with the patients by age, gender, and residency. The study protocols were approved by the Ethics Committee Research of Zhengzhou University and all participating individuals signed informed consent.

\section{Extraction and purification of peripheral blood DNA}

$2-5 \mathrm{~mL}$ of fasting peripheral venous blood was collected from subjects into tubes containing $2 \%$ EDTA- $\mathrm{Na}_{2}$ and stored in a refrigerator at $-20^{\circ} \mathrm{C}$ for subsequent assays. We used the blood genome extraction kit (DP332, Tiangen, Beijing, China) to extract genomic DNA from peripheral blood samples according to the manufacturer's recommendations and quantified by NanoDrop 2000.

\section{DNA methylation analysis}

$17 \mathrm{CpG}$ sites in the promoter of $A B C A 1$ gene were selected to make DNA methylation analysis. Bisulfite conversion of DNA was manipulated with EZ DNA methylation-gold kit (ZYMO, CA, USA) according to the manufacturer's instructions. Then, $2 \mu$ DNA sample in $20 \mu \mathrm{l}$ amplification reaction system, including $1 \mathrm{x}$ reaction buffer (TAKARA), $2 \mathrm{mM} \mathrm{Mg} 2+, 0.2 \mathrm{mM}$ dNTP, $0.1 \mu \mathrm{M}$ of each primer, $1 \mathrm{U}$ HotStarTaq polymerase (TAKARA), was amplified with PCR. The cycling program was as following: $95^{\circ} \mathrm{C}$ for $2 \mathrm{~min} ; 11 \mathrm{cycles}$ of $94^{\circ} \mathrm{C}$ for $20 \mathrm{~s}, 63^{\circ} \mathrm{C}-0.5^{\circ} \mathrm{C}$ per cycle for $40 \mathrm{~s}, 72^{\circ} \mathrm{C}$ for $1 \mathrm{~min} ; 24$ cycles of $94^{\circ} \mathrm{C}$ for $20 \mathrm{~s}, 65^{\circ} \mathrm{C}$ for $30 \mathrm{~s}, 72^{\circ} \mathrm{C}$ for $1 \mathrm{~min} ; 72^{\circ} \mathrm{C}$ for $2 \mathrm{~min}$. And

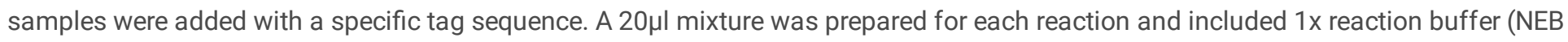

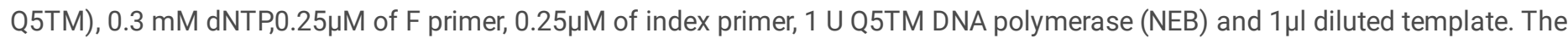
cycling program was $98^{\circ} \mathrm{C}$ for $30 \mathrm{~s} ; 11$ cycles of $98^{\circ} \mathrm{C}$ for $10 \mathrm{~s}, 65^{\circ} \mathrm{C}$ for $30 \mathrm{~s}, 72^{\circ} \mathrm{C}$ for $30 \mathrm{~s} ; 72^{\circ} \mathrm{C}$ for 5 min. Finally loaded onto Illumina Hiseq/Miseq (Illumina, San Diego, CA, USA) to analyze the results.

\section{Genotyping by Kompetitive Allele Specific PCR}

Kompetitive Allele Specific PCR technology was used to genotype the SNPs in the promoter region of $A B C A 1$ gene. DNA samples were transferred from 96 well plate to 384 well plate and then to 1536 well plate under Replicator instrument to ensure the final concentration of $10 \mathrm{ng} / \mu \mathrm{L}$. Then, 1536 plates were used to construct PCR system under Meridian instrument. Reaction system included $0.014 \mu \mathrm{L}$ 72×Assay mix, $0.04 \mu \mathrm{L}$ DNA samples, $0.5 \mu \mathrm{L}$ 2xKASP master mix, $0.446 \mu \mathrm{L} \mathrm{H}_{2} \mathrm{O}$. The cycling program was as follows: $94^{\circ} \mathrm{C}$ for 15 min; 10 cycles of $94^{\circ} \mathrm{C}$ for $20 \mathrm{~s}, 60^{\circ} \mathrm{C}$ for $60 \mathrm{~s} ; 26$ cycles of $94^{\circ} \mathrm{C}$ for $20 \mathrm{~s}, 55^{\circ} \mathrm{C}$ for $60 \mathrm{~s}$. Reading the plate on the Pharastar enzyme reader after plate was cooled and dried. Using SNP viewer of LGC genomics to analyze the results. The primer sequence for SNP genotyping was given in Table 1. 
Table 1

The primer sequence for SNP genotyping

\begin{tabular}{|c|c|c|c|}
\hline locus & Primer_Allele FAM & Primer_Allele HEX & Primer_Common \\
\hline rs2246298 & TCCCGCGCGTCTTAGGCC & СTTCCCGCGCGTCTTAGGCT & GTGGAGGGTACAGCAGGTGTCTT \\
\hline rs1800976 & CCGGGCGGGGGAAGGGG & CCGGGCGGGGGAAGGGC & GTGTCTTAGGGTCCGCGGTCT \\
\hline rs1800977 & GCAATTACGGGGTTTTTGCCGG & CGCAATTACGGGGTTTTTGCCGA & CGCTCGGTGCAGCCGAATCTA \\
\hline rs2437817 & CCAGAGCTCGTACTAGGACATC & ACCAGAGCTCGTACTAGGACATA & GGGACCGGAGGCGGTGTTAAAT \\
\hline rs539621172 & ATAAAAGGAACTAGTCCCGGCAAAAA & AAAAGGAACTAGTCCCGGCAAAAG & СССАСТСАСТСTCGCTCGCAAT \\
\hline rs2740483 & ACATAAACAGAGGCCGGGAAC & CTACATAAACAGAGGCCGGGAAG & AGCGCAGAGGTTACTATCGGTCAAA \\
\hline \multicolumn{4}{|c|}{ Detect mRNA expression of ABCA1 by RT-PCR } \\
\hline \multicolumn{4}{|c|}{$\begin{array}{l}\text { Total RNA was extracted using high efficiency blood total RNA extraction kit (DP443, Tiangen, Beijing, China) and quantified by } \\
\text { NanoDrop } 2000 \text {. Total RNA ( } 300 \text { ng for each participant) was reverse transcribed into complementary DNA (cDNA) using FastKing } \\
\text { RT Kit (Tiangen, Beijing, China). RT-PCR amplification was performed with the SYBR green PCR master mix kit (TaKaRa, Dalian, } \\
\text { China). The PCR primer pairs were as follows: } A B C A 1 \text {, forward primer: CTCAAGCACTTCCTCCGAGT, reverse primer: } \\
\text { ACTGTCCTTGGCAGCTTA } \beta \text {-actin, Forward primer: TGGCACCCAGCACAATGAA, reverse primer: } \\
\text { CTAAGTCATAGTCCGCCTAGAGCA. The PCR reaction was performed using } 7500 \text { Fast Real-Time PCR System (ThermoFisher) with } \\
\text { the following program: a pre-denaturation was at } 95^{\circ} \mathrm{C} \text { for } 30 \text { s and } 40 \text { cycles of } 95^{\circ} \mathrm{C} \text { for } 3 \mathrm{~s}, 60^{\circ} \mathrm{C} \text { for } 30 \mathrm{~s} \text {, } 95^{\circ} \mathrm{C} \text { for } 15 \mathrm{~s} \text {. The } \\
\text { dissolution curve was drawn at } 60^{\circ} \mathrm{C} \text { for } 60 \mathrm{~s}, 95^{\circ} \mathrm{C} \text { for } 15 \mathrm{~s} \text {. The internal reference was } \beta \text {-actin and the relative expression levels were } \\
\text { expressed relative to it, which was calculated with the } 2^{-\Delta \Delta C t} \text { method. }\end{array}$} \\
\hline
\end{tabular}

\section{Cell culture and Foam cells treatment}

THP-1 cells were purchased from the Cell Bank of the Chinese Academy of Sciences (Shanghai, China). The cells were cultured in RPMI1640 medium (Gibco, Grand Island, NY.) supplemented with penicillin and streptomycin and $10 \%$ fetal bovine serum (Gibco, Grand Island, NY). Cells were cultured at $37^{\circ} \mathrm{C}$ in a $5 \% \mathrm{CO}_{2}$ environment, with a medium change every $2-3$ days. All experiments were performed using cells at the logarithmic growth phase. RPMI-1640 medium supplemented with $100 \mathrm{nM}$ phorbol 12-mystriate 13-acetate (PMA, Sigma, St. Louis, USA) was used in THP-1 cells to induce monocyte differentiation into Macrophages. Macrophages were treated with $100 \mu \mathrm{g} / \mathrm{ml}$ oxLDL (Sigma, St. Louis, USA) for $12 \mathrm{~h}$ to induce foam cell formation. Foam cells were identified by oil red 0 staining. Macrophages treated with ox-LDL were fixed with $4 \%$ Paraformaldehyde for 30 min and then stained by oil red O (Sigma, St. Louis, USA) for 15 min. Finally, the cells' morphology was observed by a light microscope (Olympus, Tokyo, Japan) equipped with an imaging system at 400 magnification. Foam cells were identified by oil red 0 staining.

\section{Western blot analysis}

Total protein samples from cells were prepared with standard protocol. Equivalent amounts of protein samples were separated by $10 \%$ SDS-PAGE and transferred to PVDF film (Millipore, Billerica, USA). Film was incubated at room temperature with $5 \%$ non-fat dry milk dissolved in TBST. The membranes were then incubated in a solution with the appropriate primary antibodies (Abcam, UK) at $4^{\circ} \mathrm{C}$ and then incubated with HRP-conjugated secondary antibodies (Beyotime Biotechnology, Shanghai, China) at room temperature.

Membranes were extensively washed several times. Proteins were detected using an automatic imaging analysis system (FluorChem E, ProteinSimple, USA).

\section{Statistical analysis}

All statistical analyses were performed by the SPSS 21.0 package (SPSS Inc., Chicago, IL, USA). Quantitative variables were expressed with mean $\pm S D$ and analyzed using the Student's t-test. Statistical analyses of the methylation levels and mRNA expression among different genotypes were performed using one-way ANOVA with Bonferroni correction. Linear regression analysis was used to analyze the correlation between the methylation levels of $\mathrm{CpG}$ sites and SNPs, and the correlation between SNPs and gene expression. $P$ values less than 0.05 were considered statistically significant. The datasets generated during and/or analyzed during the current study are available from the corresponding author on reasonable request.

\section{Results}

\section{Clinical characteristics of subjects}


The clinical characteristics of the study population were shown in Table 2. The results showed no significant differences in age and sex between IS cases and controls $(P>0.05)$. Compared with the control group,the IS group had higher total cholesterol and LDL levels $(P<$ $0.05, P<0.05$ respectively). The level of HDL in the control group was higher than IS group $(P<0.05)$.

Table 2

Characteristics of study populations

\begin{tabular}{|llll|}
\hline & Cases & Controls & P value \\
\hline Sex(male/female) & $54 / 46$ & $48 / 52$ & 0.480 \\
\hline Age (mean \pm SD, years) & $59.18 \pm 11.79$ & $57.37 \pm 12.32$ & 0.290 \\
\hline Total cholesterol(mmol/L) & $5.03 \pm 1.28$ & $4.54 \pm 0.88$ & $0.002 *$ \\
\hline Total triglyceride(mmol/L) & $1.46 \pm 0.66$ & $1.39 \pm 0.77$ & 0.488 \\
\hline High-density lipoprotein(mmol/L) & $1.10 \pm 0.29$ & $1.30 \pm 0.34$ & $0.001 *$ \\
\hline Low density lipoprotein(mmol/L) & $2.84 \pm 0.72$ & $2.59 \pm 0.77$ & $0.018^{*}$ \\
\hline$* P<0.05$ denotes statistical significance. & & \\
\hline
\end{tabular}

\section{Comparison of the mRNA expression in IS cases and controls}

The mRNA expression levels of $A B C A 1$ in IS cases were significantly higher than controls (Figure $1 \mathrm{~A}, \mathrm{P}<0.05$ ). In the male group, the mRNA expression levels in IS patients were higher than controls (Figure $1 B, P<0.05$ ). However, there was no significant difference in female patients (Figure 1B, $P>0.05$ ).

(A ) mRNA expression levels of $A B C A 1$ in IS cases and controls. ${ }^{*} P<0.05$. ( $B$ ) mRNA expression levels of $A B C A 1$ in different sex in IS cases and controls. ${ }^{*} P<0.05$.

\section{Methylation levels of ABCA1 in IS cases and controls}

The average methylation level of $A B C A 1$ promoter region in the IS group was significantly lower than the control group (Figure $2 \mathrm{~A}, \mathrm{P}<$ 0.05). Gender stratification analysis showed that there was no significant difference in the methylation degree of $A B C A 1$ gene between the IS group and the control group (Figure $2 \mathrm{~B}, \mathrm{P}>0.05$ ). The methylation degree of $17 \mathrm{CpG}$ sites in the promoter region of $A B C A 1$ gene was compared. CpG1, CpG7 and CpG15 were significantly different between the two groups (Figure $2 \mathrm{C}, \mathrm{P}<0.05$ ).

(A) The average methylation levels of $A B C A 7$ 's promoter region in IS cases and controls. ${ }^{*} P<0.05$. (B) The average methylation levels of $A B C A 1$ in case group and control group in different genders. $P>0.05$. ( $C$ ) The average methylation levels of $17 \mathrm{CpG}$ sites in the promoter region of $A B C A 1$ gene in case group and control group. ${ }^{*} P<0.05$.

\section{Correlation between SNPs and methylation in ABCA1 promoter region}

To analyze the effects of SNPs of the $A B C A 1$ on methylation, a correlation between genotype and methylation was analyzed. Six SNP sites (rs1800976, rs1800977, rs2246298, rs2437817, rs2740483, rs539621172) were selected in the promoter region of $A B C A 1$ gene. Then the correlation between SNP sites and the methylation level of $17 \mathrm{CpG}$ sites in the promoter region of $A B C A 1$ gene was analyzed by linear regression. It was found that rs 2740483 , rs 1800977 and rs2437817 were significantly correlated with $\mathrm{CpG} 1$ methylation level $(P<0.05)$. Rs 1800977 was significantly correlated with CpG3 methylation level $(P<0.05)$. The average methylation level of different genotypes at CpG site is shown in Figure 3.

\section{Effect of DNA methylation of ABCA1 gene promoter on gene expression in foam cell model}

THP-1 foam cell model was constructed to explore whether DNA methylation of $A B C A 1$ gene promoter affected the expression of $A B C A 1$ mRNA. Oil red 0 staining indicated THP-1 foam cell model was successfully established (Figure 4A). Firstly, mRNA expression of $A B C A 1$ increased significantly after foam cells formation (Figure $4 \mathrm{~B}, \mathrm{P}<0.05$ ). And then, the expression of $A B C A 1$ protein was analyzed. The expression of ABCA1 protein in foam cells was significantly higher than THP-1 cell lines (Figure $4 C, P<0.05$ ).

After THP-1 derived foam cells were formed, the average methylation level of the promoter region of ABCA 1 gene decreased. However, there was no significant difference (Figure 4D). Then, it was analyzed to the methylation level of $17 \mathrm{CpG}$ sites in the promoter region of 
ABCA1 gene, and found that the methylation level of $\mathrm{CpG1}, \mathrm{CpG} 11$ and $\mathrm{CpG} 16$ sites decreased significantly after foaming ((Figure 4E, $\mathrm{P}$ $<0.05)$.

\section{Discussion}

ATP binding cassette transporter A1 (ABCA1) mediates the efflux of cholesterol and phospholipids from peripheral cells and binds to ApoA-1, which plays an important role in reverse cholesterol transport (RCT) and involve in the development of atherosclerosis (Kim $\mathrm{J}$ et al., 2009). The occurrence and development of atherosclerosis is an important pathophysiological basis of ischemic stroke. Baird et al. found that peripheral blood leukocytes can migrate to cerebral ischemic foci, and the change of gene expression level can be found through peripheral blood leukocyte detection, which can represent the change of local brain microenvironment (Baird AE, 2007). In order to understand the difference of gene expression in brain and blood, Qi t et al. analyzed the correlation between gene expression and methylation quantitative trait loci in brain and blood, and found that the genetic effect of gene expression and methylation quantitative trait loci was highly correlated between brain and blood samples (Qi T et al., 2018).

In this study, 100 patients with IS and 100 healthy controls were selected and the expression of $A B C A 1$ gene in peripheral blood was detected by real-time RT-PCR. The results showed that the mRNA expression of $A B C A 1$ in IS group was significantly higher than control group $(P<0.05)$. The relative mRNA expression of $A B C A 1$ in male patients was significantly higher than control group $(P<0.05)$, but there was no significant difference in female patients $(P \otimes 0.05)$. Our results were consistent with the following reports. Demina et al. cultured macrophages from patients with artery stenosis and healthy controls for 5 days in vitro and found that the mRNA expression of $A B C A 1$ in macrophages of patients was significantly higher than controls $(P<0.05)$ (Demina EP et al., 2013). Albrecht et al. analyzed the mRNA expression of $A B C A 1$ in atherosclerotic plaques of patients undergoing carotid endarterectomy (CEA) and normal arteries, and found that the mRNA expression of $A B C A 1$ in atherosclerotic plaques was significantly increased $(P<0.05)$ (Albrecht $\mathrm{C}$ et al., 2004). Rupture of atherosclerotic plaque will increase the risk of IS. Heo et al. found that the mRNA expression of $A B C A 1$ and protein in ruptured plaque was significantly higher than unruptured plaque, which proved that $A B C A 1$ was involved in plaque rupture process (Heo $\mathrm{SH}$ et al., 2018). ABCA1 can inhibit the secretion of inflammatory cytokines to mediate immune response and play an anti atherosclerotic role. The increased of ABCA1 expression promotes plaque rupture, and then participated in the pathological process of IS.

DNA methylation is one of the most important epigenetic modifications. DNA methylation affects the expression of genes. Therefore, the methylation levels of $A B C A 1$ gene promoter region were detected by MethyTarget sequencing in 100 patients with IS and 100 healthy control. The results indicated that the average methylation level in IS group was significantly lower than the control group $(P<0.05)$. In addition, the methylation level of $17 \mathrm{CpG}$ sites in the promoter of $A B C A 1$ gene were analyzed and the DNA methylation levels of $\mathrm{CpG1}, \mathrm{CpG7}$ and $\mathrm{CpG15}$ sites in IS group was significantly lower than control group $(P<0.05)$. The methylation level of $\mathrm{CpG}$ sites in the promoter region of ABCA 1 gene also increased in a coronary artery disease study by Guay et al (Guay S-P et al., 2012). Our results suggested that the methylation level of $A B C A 1$ promoter was negatively correlated with ABCA1 expression. Hypomethylation of $A B C A 1$ gene promoter region promotes the expression of $A B C A 1$ gene in patients with IS. The results of our study are similar to Guay et al (Guay S-P,Brisson D,Munger J,Lamarche B,Gaudet D and Bouchard L, 2012).

SNP sites can affect the methylation level of $\mathrm{CpG}$ sites, which was suggested as a potential epigenetic mechanism to affect gene function and then participate in the occurrence and development of diseases. Thus, six SNP sites (rs1800976, rs1800977, rs2246298, rs2437817, rs2740483, rs539621172) were selected in the promoter region of $A B C A 1$ gene. Then, analyzed the correlation between SNPs and the methylation level of $17 \mathrm{CpG}$ sites by linear regression. The results showed that rs2740483, rs1800977 and rs2437817 were significantly correlated with CpG1 methylation level $(P<0.05)$. Rs 1800977 was significantly correlated with CpG3 methylation level $(P<0.05)$. Therefore, we speculated that rs2740483, rs1800977 and rs2437817 affected the methylation level of CpG site in the promoter region of $A B C A 1$ gene, and thus affected the mRNA expression of $A B C A 1$.

Foam cells are the earliest pathological cells after atherosclerotic lesions (Nakashima Y et al., 2007). Studies have shown that foam cells mainly derived from phagocytosis of lipid molecules by macrophages differentiated by monocytes. Therefore, we constructed foam cells derived from THP-1 macrophages, and compared the mRNA expression and protein of $A B C A 1$ gene in monocytes and foam cells. The results showed that the mRNA expression of $A B C A 1$ in the foam cell group was significantly higher than THP-1 cell group $(P<0.05)$, which was consistent with the results of mRNA extracted from peripheral venous blood of IS patients. Next, the protein expression of ABCA1 was detected by Western Blot. The protein expression of ABCA1 in foam cells was significantly higher than the THP-1 cell line $(P<0.05)$, which was consistent with the relative expression of mRNA. Geeraert $\mathrm{B}$ et al. found that the relative expression 
levels of $A B C A 1$ gene mRNA and protein in human blood mononuclear cells were consistent and appeared before the formation of atherosclerotic plaques (Geeraert B et al., 2007). This was consistent with our results. Song et al. explored the effects of the ratio of N-6 to n-3PUFA on the formation of THP-1 monocyte-derived foam cells and found that the mRNA expression of $A B C A 1$ significantly increased after the induction of THP-1 cells by ox-LDL (Song $Z$ et al., 2018). We speculated that after adding ox-LDL to form foam cells, the expression of $A B C A 1$ gene and protein would increase for maintain the balance of lipid metabolism in the cells.

Liang et al. found that the methylation level of the genome of THP-1 cells decreases after foaming in the study of Homocysteine (Hcy) as a prevalent risk factor for cardiovascular events(Liang Y et al., 2013). After THP-1 cells differentiate into foam cells, what happens to the methylation level of $A B C A 1$ gene promoter? Therefore, the methylation level of $A B C A 1$ gene promoter region in THP-1 cells and foam cells was compared by MethylTarget sequencing technology. The results showed that the average methylation level of foam cells was lower than THP-1 monocytes, but there was no significant difference $(P>0.05)$. Then we continued to analyze the methylation level of $17 \mathrm{CpG}$ sites in the promoter region of $A B C A 1$ gene. Compared with THP-1 cells, the methylation of CpG1, CpG11 and CpG16 in foam cells decreased significantly $(P<0.05)$. After foam cell formation, the promoter region of $A B C A 1$ gene showed a hypomethylation state, and the gene expression level was significantly increased, which precedes the formation of atherosclerotic plaques, and had a certain predictive effect on atherosclerotic stroke. The hypomethylation of $A B C A 1$ gene might be used as a potential marker of atherosclerotic stroke.

The present study includes several limitations. Firstly, the expression levels of the ABCA1 protein were not explored in the IS patients and control subjects. Secondly, a potential selection bias may have been present since the cases and controls were recruited from the same hospitals.

In summary, the present study demonstrated that the rs 2740483 , rs1800977 and rs2437817 affect the methylation level of $A B C A 1$ gene promoter, thereby affecting the mRNA expression and protein of ABCA1, changing the clearance rate of intracellular lipid, and involve in the pathogenesis of IS. Besides, the hypomethylation status of $A B C A 1$ gene might be used as a potential marker of atherosclerotic stroke.

\section{Declarations}

\section{Data availability statement}

The datasets generated during and/or analyzed during the current study are available from the corresponding author on reasonable request.

\section{Ethical statement}

\section{Ethics approval and consent to participate}

The study protocols were approved by the Ethics Committee on Human Research of Zhengzhou University and informed written consent was obtained from each participant. All experiments were performed in accordance with relevant guidelines and regulations. All patients provided written informed consent.

\section{Consent for publication}

The Author confirms: that the work described has not been published before; that it is not under consideration for publication elsewhere; that its publication has been approved by all co-authors, if any.

\section{Availability of data and materials}

The datasets generated during and/or analyzed during the current study are available from the corresponding author on reasonable request.

\section{Competing interests}

The authors declare that they have no conflicts of interest with the contents of this article.

\section{Funding}


Research reported in this publication were supported by the National Natural Science Foundation of China- Henan United fund (No. U2004114) and National Natural Science Foundation of China (No. 81571154)

\section{Authors' contributions}

J.W, S.D.Y, Y.L, performed experiments. Z.J.Z, Y.P, T.Y.H, D.Z.Y. conducted the statistical analysis. A.F.L, H.Y.H, B.X.Z, Y.Y.L, Y.X. were involved in local study implementation and participant recruitment. Y.H, Z.H.L. wrote the manuscript. H.Z, G.Y.S, J.J. conceived of the study, and participated in its design and coordination. All authors read and approved the final version of the manuscript.

\section{Acknowledgement}

We acknowledge the technical assistance of staff members of the Neurology Department of the First People's Hospital of Zhengzhou and departments of neurology in the First Affiliated Hospital of Henan University of Chinese Medicine. We also thank all patients and controls for providing blood samples.

\section{References}

Albrecht C, Soumian S, Amey JS, Sardini A, Higgins CF, Davies AH, Gibbs RG (2004), ABCA1 expression in carotid atherosclerotic plaques. Stroke 35:2801-2806.https://doi.org/10.1161/01.STR.0000147036.07307.93

Baird AE (2007), Blood genomics in human stroke. Stroke 38:694-698.https://doi.org/10.1161/01.STR.0000250431.99687.7b

Banerjee C, Chimowitz MI (2017), Stroke Caused by Atherosclerosis of the Major Intracranial Arteries. Circ Res 120:502513.https://doi.org/10.1161/CIRCRESAHA.116.308441

Cheung WA, Shao X, Morin A, Siroux V, Kwan T, Ge B, Aissi D, Chen L, et al. (2017), Functional variation in allelic methylomes underscores a strong genetic contribution and reveals novel epigenetic alterations in the human epigenome. Genome Biol 18:50.https://doi.org/10.1186/s13059-017-1173-7

Das PM, Singal R (2004), DNA methylation and cancer. J Clin Oncol 22:4632-4642.https://doi.org/10.1200/JC0.2004.07.151

Demina EP, Miroshnikova VV, Maiorov NV, Davydenko VV, Shvartsman AL (2013), [ABCA1 mRNA and protein levels in M-CSF-activated macrophages from patients with arterial stenosis]. Tsitologiia 55:580-585

Favari E, Chroni A, Tietge UJ, Zanotti I, Escola-Gil JC, Bernini F (2015), Cholesterol efflux and reverse cholesterol transport. Handb Exp Pharmacol 224:181-206.https://doi.org/10.1007/978-3-319-09665-0_4

Galkina E, Ley K (2009), Immune and inflammatory mechanisms of atherosclerosis (*). Annu Rev Immunol 27:165197.https://doi.org/10.1146/annurev.immunol.021908.132620

Geeraert B, De Keyzer D, Davey PC, Crombe F, Benhabiles N, Holvoet P (2007), Oxidized low-density lipoprotein-induced expression of ABCA1 in blood monocytes precedes coronary atherosclerosis and is associated with plaque complexity in hypercholesterolemic pigs. $J$ Thromb Haemost 5:2529-2536.https://doi.org/10.1111/j.1538-7836.2007.02786.x

Gibbs JR, van der Brug MP, Hernandez DG, Traynor BJ, Nalls MA, Lai SL, Arepalli S, Dillman A, et al. (2010), Abundant quantitative trait loci exist for DNA methylation and gene expression in human brain. PLoS Genet 6:e1000952.https://doi.org/10.1371/journal.pgen.1000952

Gomez-Uriz AM, Milagro FI, Mansego ML, Cordero P, Abete I, De Arce A, Goyenechea E, Blazquez V, et al. (2015), Obesity and ischemic stroke modulate the methylation levels of KCNQ1 in white blood cells. Hum Mol Genet 24:1432-

1440.https://doi.org/10.1093/hmg/ddu559

Guay S-P, Brisson D, Munger J, Lamarche B, Gaudet D, Bouchard L (2012), ABCA1 gene promoter DNA methylation is associated with HDL particle profile and coronary artery disease in familial hypercholesterolemia. Epigenetics 7:464-

472.https://doi.org/10.4161/epi.19633 
Heo SH, Lee E-H, Park H-H, Kim BJ, Youn HC, Kim YS, Kim HY, Koh S-H, et al. (2018), Differences between the Molecular Mechanisms Underlying Ruptured and Non-Ruptured Carotid Plaques, and the Significance of ABCA1. Journal of stroke 20:80-

91.https://doi.org/10.5853/jos.2017.02390

Huo Y, Ley K (2001), Adhesion molecules and atherogenesis. Acta Physiol Scand 173:35-43.https://doi.org/10.1046/j.1365-

201X.2001.00882.x

Kaplan M, Aviram M (2001), Retention of oxidized LDL by extracellular matrix proteoglycans leads to its uptake by macrophages: an alternative approach to study lipoproteins cellular uptake. Arterioscler Thromb Vasc Biol 21:386-

393.https://doi.org/10.1161/01.atv.21.3.386

Kim J, Basak JM, Holtzman DM (2009), The role of apolipoprotein E in Alzheimer's disease. Neuron 63:287-

303.https://doi.org/10.1016/j.neuron.2009.06.026

Liang Y, Yang X, Ma L, Cai X, Wang L, Yang C, Li G, Zhang M, et al. (2013), Homocysteine-mediated cholesterol efflux via ABCA1 and ACAT1 DNA methylation in THP-1 monocyte-derived foam cells. Acta Biochimica et Biophysica Sinica 45:220-

228.https://doi.org/10.1093/abbs/gms119

McGill HC, Jr., McMahan CA, Herderick EE, Tracy RE, Malcom GT, Zieske AW, Strong JP (2000), Effects of coronary heart disease risk factors on atherosclerosis of selected regions of the aorta and right coronary artery. PDAY Research Group. Pathobiological Determinants of Atherosclerosis in Youth. Arterioscler Thromb Vasc Biol 20:836-845.https://doi.org/10.1161/01.atv.20.3.836

Nakashima Y, Fujii H, Sumiyoshi S, Wight TN, Sueishi K (2007), Early human atherosclerosis: accumulation of lipid and proteoglycans in intimal thickenings followed by macrophage infiltration. Arteriosclerosis, thrombosis, and vascular biology 27:1159-1165

Qi T, Wu Y, Zeng J, Zhang F, Xue A, Jiang L, Zhu Z, Kemper K, et al. (2018), Identifying gene targets for brain-related traits using transcriptomic and methylomic data from blood. Nat Commun 9:2282.https://doi.org/10.1038/s41467-018-04558-1

Skalen K, Gustafsson M, Rydberg EK, Hulten LM, Wiklund O, Innerarity TL, Boren J (2002), Subendothelial retention of atherogenic lipoproteins in early atherosclerosis. Nature 417:750-754.https://doi.org/10.1038/nature00804

Song Z, Xia H, Yang L, Wang S, Sun G (2018), Lowering the n-6/n-3 PUFAs ratio inhibits the formation of THP-1 macrophage-derived foam cell. Lipids Health Dis 17:125.https://doi.org/10.1186/s12944-018-0772-y

Virani SS, Alonso A, Benjamin EJ, Bittencourt MS, Callaway CW, Carson AP, Chamberlain AM, Chang AR, et al. (2020), Heart Disease and Stroke Statistics-2020 Update: A Report From the American Heart Association. Circulation 141:e139-

e596.https://doi.org/10.1161/CIR.0000000000000757

\section{Figures}


A

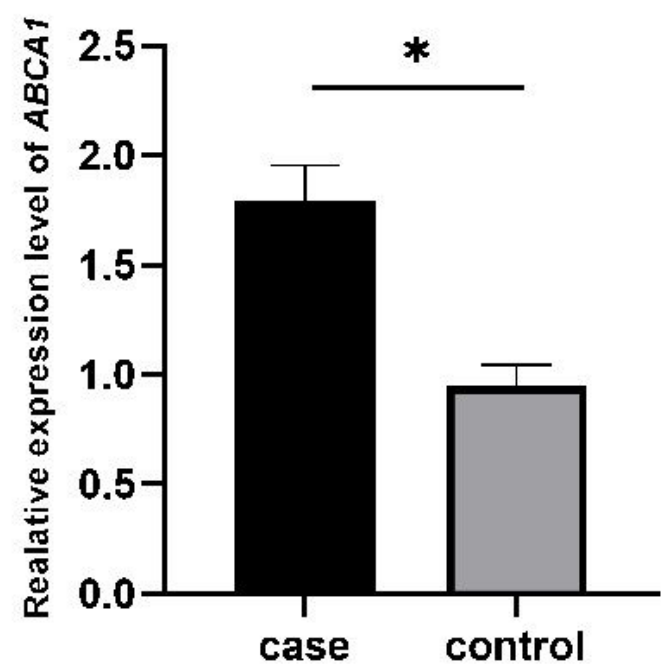

B

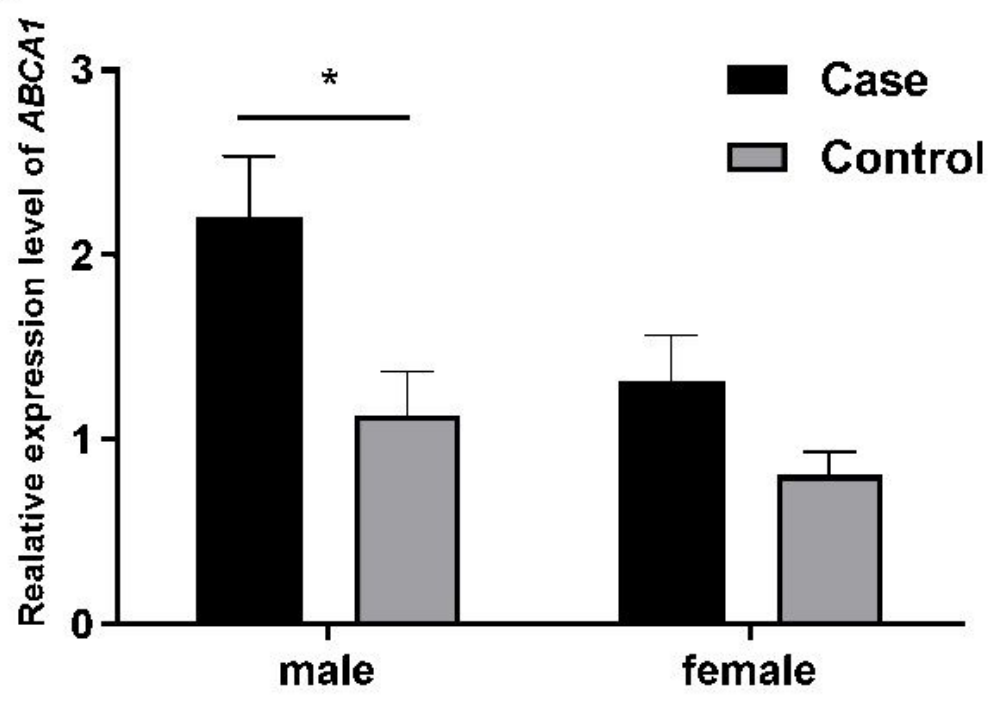

Figure 1

(A ) mRNA expression levels of ABCA1 in IS cases and controls. ${ }^{*} \mathrm{P}<0.05$. ( B ) mRNA expression levels of ABCA1 in different sex in IS cases and controls. * $\mathrm{P}<0.05$. 
A

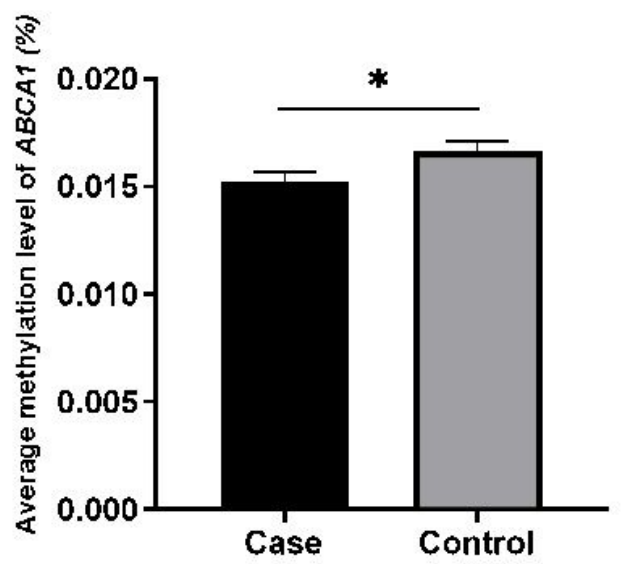

C

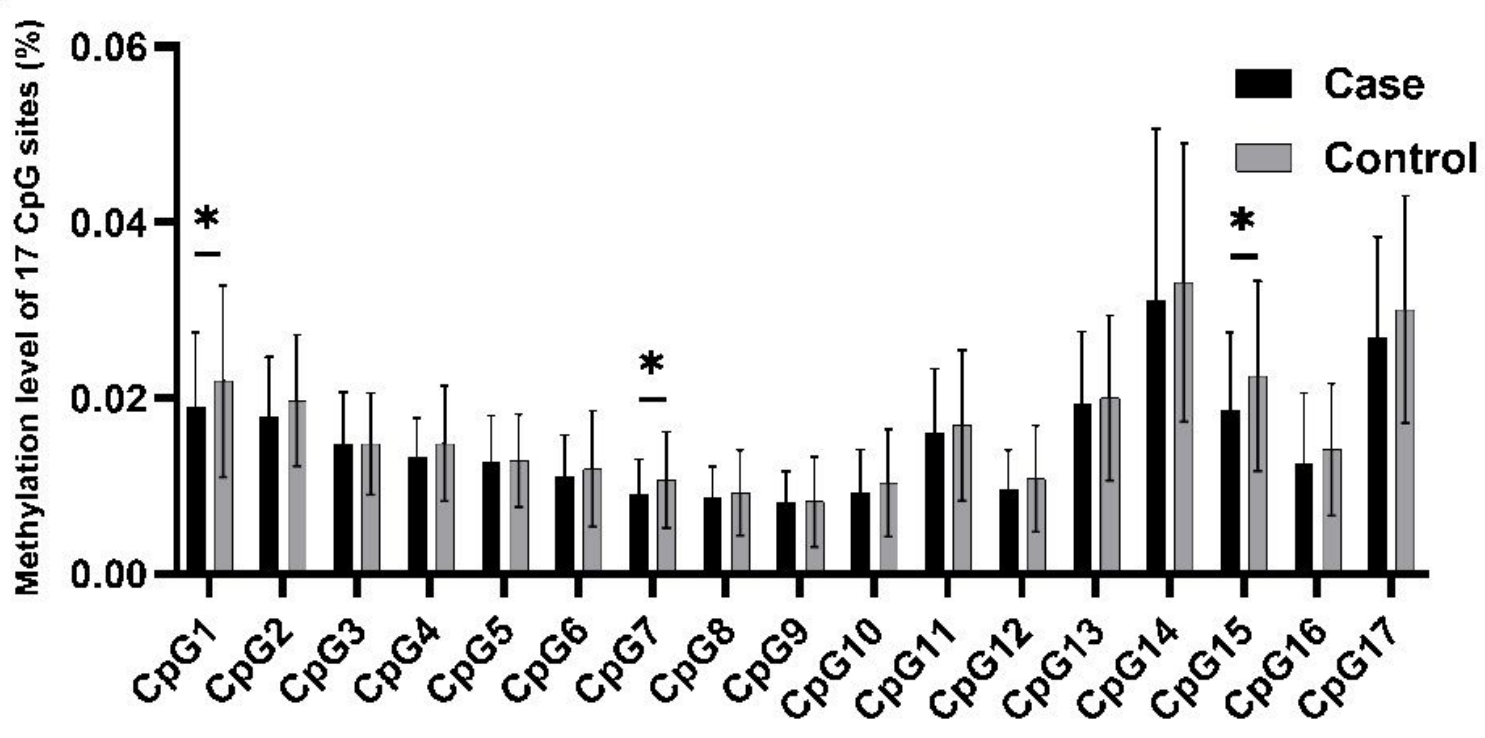

Figure 2

(A) The average methylation levels of ABCA1's promoter region in IS cases and controls. ${ }^{*} P<0.05$. (B) The average methylation levels of $A B C A 1$ in case group and control group in different genders. $P>0.05$. (C) The average methylation levels of $17 \mathrm{CpG}$ sites in the promoter region of $\mathrm{ABCA} 1$ gene in case group and control group. ${ }^{*} \mathrm{P}<0.05$. 
A

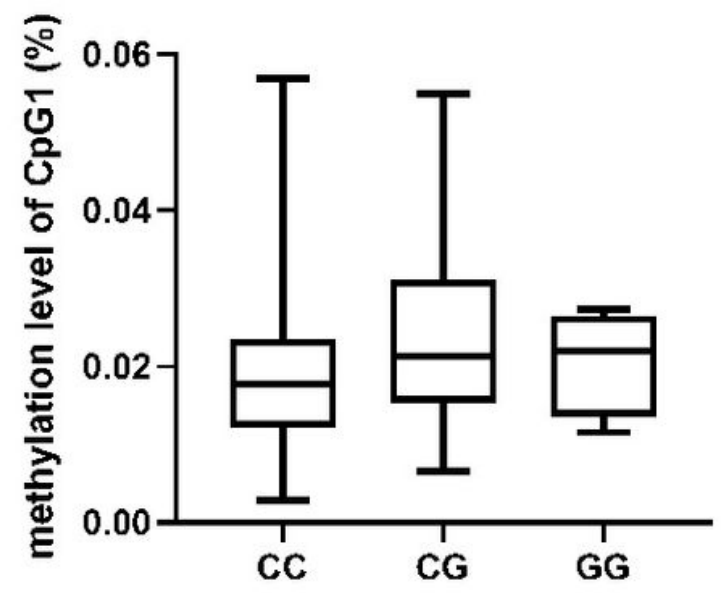

$\mathrm{C}$

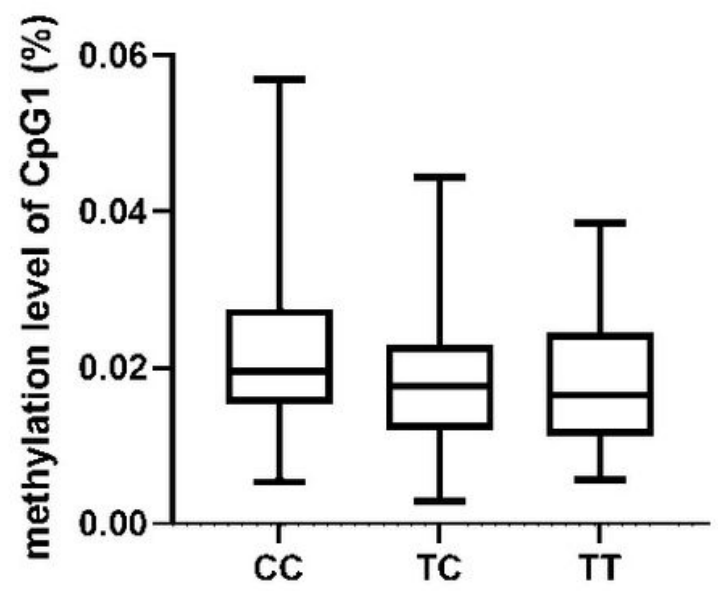

B
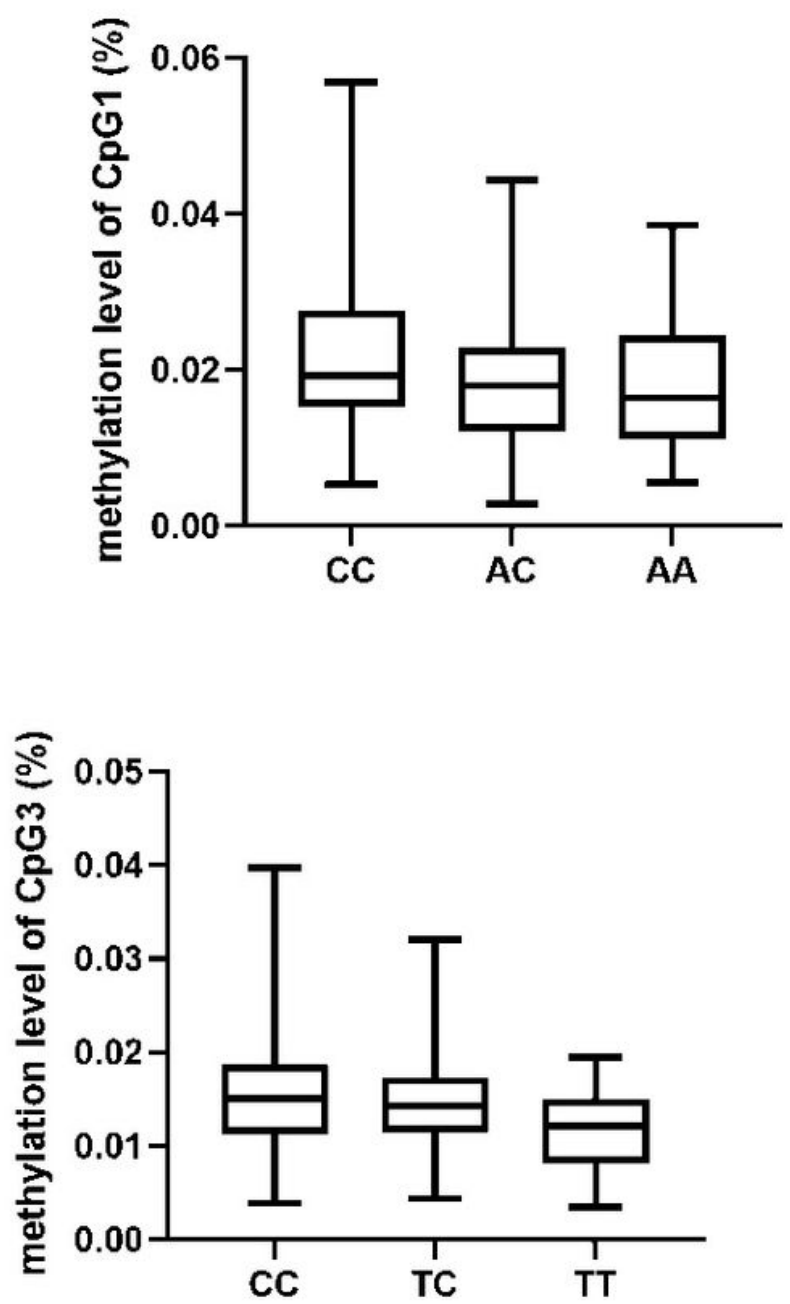

Figure 3

(A) The average methylation level of different genotypes at rs2740483. (B) The average methylation level of different genotypes at rs2437817. ( C) The average methylation level of different genotypes at rs1800977. 

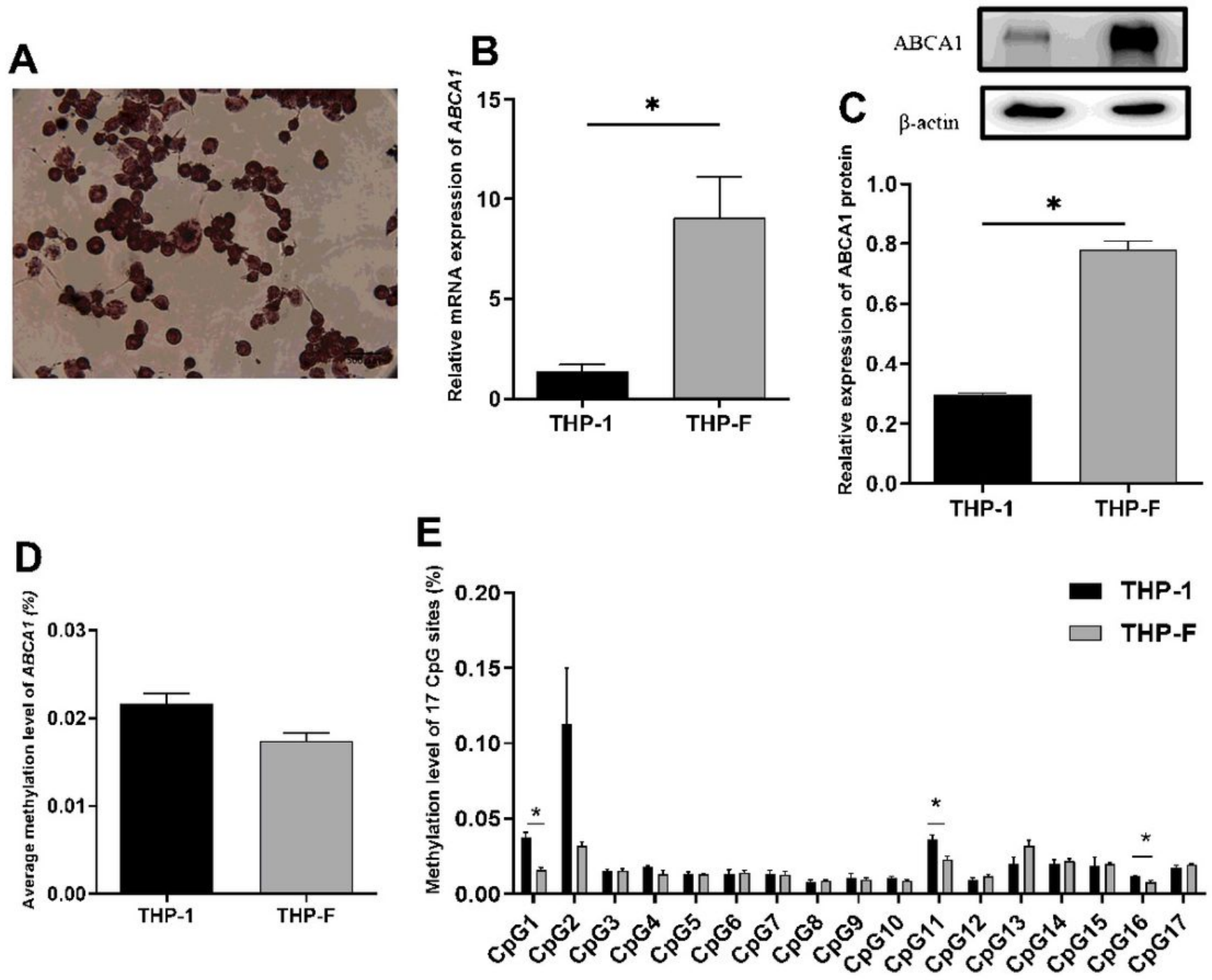

Figure 4

(A) Oil red 0 staining of THP-1 foam cells. ( B ) The relative expression level of ABCA1 mRNA in THP-1 and THP-1 foam cells. * P < 0.05. ( C ) The relative expression level of ABCA1 protein in THP-1 and THP-1 foam cells. ${ }^{P}<0.05$. (D) The average methylation level of ABCA1 gene promoter region in THP-1 cells and THP-1 derived foam cells. *P > 0.05. ( $E$ ) The average methylation level of CpG sites in the promoter region of ABCA1 gene. * $\mathrm{P}<0.05$

\section{Supplementary Files}

This is a list of supplementary files associated with this preprint. Click to download.

- Additionalfile.xlsx 